\title{
Insurance Salespeople's Attitudes towards Collusion: The Case of Taiwan's Car Insurance Industry
}

\author{
Lu-Ming Tseng a and Wen-Pin $\mathrm{Su}^{\mathrm{b}}$ \\ ${ }^{a}$ Department of Risk Management and Insurance, Feng Chia University, No. 100 Wenhwa Rd., Seatwen, \\ Taichung, Taiwan 40724, R.O.C. \\ E-mail: Lmtseng@fcu.edu.tw \\ ${ }^{\mathrm{b}}$ Department and Graduate Institute of Insurance, Chaoyang University of Technology, 168, Jifeng E. Rd., \\ Wufeng District, Taichung, 41349 Taiwan, R.O.C. \\ E-mail: suwp@cyut.edu.tw
}

Insurance researchers believe that the increase in insurance fraud may be associated with the unethical decisions made by some insurance salespeople. However, to date, research that has empirically investigated the link between insurance salespeople and collusion is scant. Using the car insurance industry in Taiwan as an example, this paper explores the impact of the opportunity to obtain the fraudulent claim and that of the size of actual loss on car insurance salespeople's attitudes towards collusion in situations involving contract renewal and non-covered loss. The results showed that the size of actual loss and the fraud type (customer fraud vs insider fraud) may correlate with the decision-making of the car insurance salespeople. It seemed that the responders have a higher acceptance of customer fraud rather than insider fraud. Empirical research on insurance salespeople's attitudes towards salespeople-customer collusion is very rare. This study may make some contribution to insurance research and practice.

The Geneva Papers (2014) 39, 25-41. doi:10.1057/gpp.2013.4

Keywords: insurance fraud; contract renewal; loss; salespeople; collusion

Article submitted 2 April 2012; accepted 21 December 2012; published online 22 May 2013

\section{Introduction}

Insurance salespeople usually face a range of ethical dilemmas that relate to customer moral hazard. A customer may misrepresent facts on an insurance claim application, or a customer may ask insurance salespeople to be involved in deception or collusion. In this situation, honest salespeople should reject the unethical request and ask the customer to behave in a truthful manner. However, the ethical request may not bring the salespeople a desirable outcome. In this situation, some insurance salespeople may even turn a blind eye to customer dishonesty, or help customers to do unethical things (e.g. provide untruthful information about customers to the insurance company) in exchange for future favours (e.g. customer repurchase). In this case, dishonest salespeople may sacrifice the interests of the insurer to satisfy customers and their own interests.

Insurance researchers also believe that the increase in insurance frauds may be associated with the unethical decisions made by some insurance salespeople. ${ }^{1}$

\footnotetext{
${ }^{1}$ For example Picard (2000); Viaene and Guido (2004).
} 
For example, in his analysis of insurance fraud, Picard ${ }^{2}$ has depicted the collusion between policyholders and sales agents, and argued that

there is some scope for collusion between agents and policyholders which facilitates insurance fraud. The agent may be aware of the fact that the customer tells lies or that he conceals relevant information but he overlooks this violation in order not to miss an opportunity to sell one more insurance policy. Hence, in such a case, the defrauder is in fact the policyholder-agent coalition itself. ${ }^{2}$

Picard's ${ }^{2}$ research has revealed the importance of the agents' control in insurance fraud problems.

However, considering the widespread occurrence of insurance frauds in the industry, there is currently very little research focusing on insurance salespeople's attitudes towards insurance frauds. Given that insurance salespeople are one of the most important marketing channels in the insurance industry and are also important for the insurance customers, we think the issue of salespeople-customer collusion may deserve some attention. Furthermore, as insurance salespeople help their customers choose insurance policies and settle insurance claims (in the event of loss), it is possible for insurance salespeople to hold some private information about customers. ${ }^{2}$ Hence, the purpose of this paper is to explore insurance salespeople's attitudes towards salespeople-customer collusion. More specifically, this research focuses on the impacts of the opportunity to obtain the fraudulent claim and the size of actual loss on car insurance salespeople's acceptance of salespeople-customer collusion in situations involving contract renewal and non-covered loss.

Findings from this study may provide some contributions to the insurance fraud literature. For instance, by examining insurance salespeople's attitudes towards salespeople-customer collusion, our knowledge of insurance frauds could be extended. In addition, understanding the insurance frauds arising from salespeople-customer collusion based on the responses from full-time insurance salespeople may allow insurance practitioners to look at the insurance fraud problem in a more practical way.

\section{Background and literature}

On the basis of the research purpose of this study, the relevant discussion of this paper is organised as follows. First, we explain the relationship between contract renewal/ non-covered loss and insurance fraud. Then, we explore the relationship between outcome uncertainty (perceived opportunity to obtain the fraudulent claim) and salespeople's perceptions of an insurance fraud. Finally, we investigate the relationship between the size of actual loss and salespeople's perceptions of an insurance fraud.

\section{Contract renewal}

In the insurance industry, contract renewal refers to the continuation by the policyholder of the insurance policy for an additional period of time, when the initial

\footnotetext{
${ }^{2}$ Picard (2000, p. 353).
} 
period of insurance has expired. The contract renewal process can be different across countries. In some countries, the car insurance contract would be automatically renewed for another year if the policyholders did not cancel the policy one month before expiration (or before the end of the insurer's notice). However, in Taiwan, car insurance companies have to send a paper-based notice to the customers to remind them about the contract expiration, and those companies cannot renew the insurance policy if they have not obtained the paper-based agreement from the customer. Policyholders in Taiwan are free to reject the insurer's offer when the notice has been delivered to them, or the car insurance contracts become "automatically invalid" if the customer does not reply to the insurer's notice before the expiration date. Of course there is an exception. If a Taiwanese policyholder decides to renew his car insurance in the automatic manner, she/he can sign the paper-based agreement at the beginning. In practice, however, car insurance companies in Taiwan still have to send the paper-based notice to the customer to remind her/him that the contract will be renewed for the coming year.

\section{Contract renewal and insurance frauds}

In the car insurance industry, the contract renewal rate is an important factor that determines salespeople's incomes. Maintaining a high renewal rate is also important for the insurer. However, there could be a link between the need for contract renewal and moral hazard. Picard ${ }^{2}$ argued that agents are likely to offer unjustified benefits to dishonest policyholders in order to compensate for promotional efforts. Contract renewal therefore could produce incentives for the insurance salespeople to be involved in salespeople-customer collusion (e.g. in exchange for renewal of the contract, salespeople may help the customer provide untruthful information to the insurer).

This idea is plausible if we look at the salespeople-customer collusion problem based on Molm, Takahashi and Peterson's research about reciprocal exchange. According to Molm et al. ${ }^{3}$ reciprocal exchange refers to informal agreements to give goods, services, information or money in exchange for future compensation in kind. In the insurance industry, salesperson-customer collusion may also involve some reciprocal activities between policyholders and insiders. That is an insurance salesperson can help a customer to provide untruthful information about the loss, and then the customer may return the contract renewal as a favour to the salesperson.

\section{Non-covered loss and insurance frauds}

In Taiwan, a comprehensive vehicle policy provides comprehensive coverage for natural disaster, vandalism and moving collision. Logically, when the damages are caused by vandalism, policyholders with comprehensive coverage will be reimbursed, while policyholders with no protection against vandalism (a non-comprehensive vehicle policy) should get no compensation. However, possible moral hazard may occur in this situation, ${ }^{4}$ that is, a policyholder may file the claim even if the damages

\footnotetext{
${ }^{3}$ Molm et al. (2000).

${ }^{4}$ Tennyson (2002).
} 
are not covered by the policy (e.g. they could submit claims by saying the damages were caused by natural disasters).

Three reasons for this kind of unethical behaviour are stated. First, insurance fraud is deeply associated with information asymmetry. ${ }^{5}$ An example is given by Dionne and St-Michel. ${ }^{6}$ They found that, when greater information asymmetry was involved (e.g. some illnesses were hard to diagnose), the increase in insurance coverage could positively affect the duration of a worker's absence from work. Second, insurance fraud is associated with ethical attitudes (EAs). Previous research found that some people do not perceive claim fraud to be an ethical problem. ${ }^{7}$ Tennyson ${ }^{4}$ further argued that the prevalence of opportunistic fraud is directly related to consumer attitudes. Finally, the perception of corporate unfairness may result in claim frauds. For example, it was argued that a high deductible amount may result in fraudulent customer claims. ${ }^{8}$ In summary, information asymmetry, customer attitudes and perception of unfairness could be the reasons for the insurance frauds.

\section{Perceived opportunity to obtain the fraudulent claim}

Researchers have shown a significant relationship between opportunity factors and criminal decision-making. For example, Cohen ${ }^{9}$ showed that opportunity factors such as the incidence of persons living alone or the presence of lightweight durable goods may provide criminals with opportunities to carry out the crimes. In other research, LaGrange and Silverman ${ }^{10}$ found that smoking and drinking behaviour among students was linked to parental supervision and monitoring (parental supervision can be taken as an opportunity factor). Research on cybercrime also showed that a significant portion of this one source of financial loss was attributable to insider (e.g. employee) computer crime. ${ }^{11}$ The finding suggested the importance of security controls, and security controls can be taken as an opportunity factor within the organisations. In the insurance literature, Viaene and Guido ${ }^{12}$ also pointed out that insurance fraud is the product of both motivation and opportunity. According to this concept, it is plausible that salespeople-customer collusion may be more likely to occur when the opportunity to obtain the fraudulent claim is high.

In fact, some insurance companies may have very strict claims management procedures while some insurers are much more lenient in their claims polices. In some cases, claim adjusters pay the claim immediately, just because the claim size is very small. Insurance salespeople may have private information about the claims management processes (because they are employees of the insurance companies), and this information could be considered as an opportunity factor in the salespeople-customer

\footnotetext{
5 Arrow (1963).

${ }^{6}$ Dionne and St-Michel (1991).

${ }^{7}$ Tennyson (1997, p. 36).

${ }^{8}$ Dionne and Gagné (2001); Miyazaki (2009).

${ }^{9}$ Cohen (1981).

${ }^{10}$ LaGrange and Silverman (1999).

${ }^{11}$ Nykodym et al. (2005).

12 Viaene and Guido (2004).
} 
collusion problem. We think perceived opportunity to obtain the fraudulent claim will be positively related to the insurance salespeople's intention to engage in collusion. A hypothesis is proposed.

Hypothesis 1: Car insurance salespeople would be more likely to engage in collusion when the perceived opportunity to obtain the fraudulent claim is high rather than low.

\section{The size of actual loss}

Jones's ${ }^{13}$ idea about magnitude of consequences could also explain why a small fraud is more tolerable by the experts (e.g. salespeople, investigators or claim managers). The magnitude of consequences is defined as the sum of the harms done to victims of the moral act in question. ${ }^{13}$ Basically, the greater the perceived magnitude of the consequences, the higher the perceived level of moral intensity. ${ }^{14}$ Haines et al. ${ }^{15}$ also argued that unethical behaviour with a high magnitude of consequences could be more unacceptable. These findings may suggest that frauds with small consequences are more likely to be accepted because people believe that small frauds generally have smaller impacts on others. In sum, it would be expected that a fraud with a low magnitude of consequences could be seen as more acceptable. Thus, in cases of small frauds perceived by the car insurance salespeople, the car insurance salespeople may be more willing to engage in the collusion. A hypothesis is proposed.

Hypothesis 2: Car insurance salespeople would be more likely to engage in collusion when the actual loss is small rather than large.

\section{Methodology}

This paper explores the impact of the opportunity to obtain the fraudulent claim and of the size of actual loss on car insurance salespeople's attitudes towards collusion in situations involving contract renewal and non-covered loss. The research purpose requires the utilisation of four different experimental conditions, including two levels of opportunities to obtain the fraudulent claim and two levels of loss sizes. In other words, our research hypotheses were tested using a 2 (opportunities to obtain the fraudulent claim) $\times 2$ (loss sizes) experimental design (see Table 1). We use four versions of questionnaires (versions $\mathrm{A}, \mathrm{B}, \mathrm{C}, \mathrm{D})$ to represent the four different experimental conditions.

The reasons for using questionnaires are as follows. First, to ensure the anonymity of respondents when investigating sensitive issues (such as personal attitudes towards insurance collusion), using anonymous questionnaires is suggested. ${ }^{16}$ Second, to study the impact of loss sizes and of opportunities to obtain the fraudulent claim on car

\footnotetext{
13 Jones (1991, p. 374).

${ }^{14}$ Singhapakdi et al. (1996); Chen et al. (2009).

15 Haines et al. (2008).

${ }^{16}$ Dooley (2001).
} 
Table 1 Scenario 1 (Customer fraud)

Version A "Q" is a car insurance salesperson. A customer of Q's had a car insurance policy with a
validity period extending from 1 January 2008 to 31 December 2008. According to the
insurance policy, the loss from vandalism was covered. Unfortunately, on 1 January 2009, the
car was vandalised by an unknown person and this made the customer suffer a loss of
NT\$5,000 for the car repair. To obtain the insurance money, the customer asked Q to apply
for the claim and say the loss was caused on 31 December 2008. In exchange for Q's
cooperation, the customer said to Q that he would renew the insurance policy for the following
year.
On the basis of Q's knowledge, Q knows that the claim department will definitely pay the
claim.

Version B The contents of the scenario are the same as version A except for ...

* On the basis of Q's knowledge, Q knows that there is only a 30 per cent chance that the claim department will pay the claim.

Version $\mathrm{C}$ The contents of the scenario are the same as version A except for...

* Unfortunately, on 1 January 2009, the car was vandalised by an unknown person and this made the customer suffer a loss of NT\$100,000 for the car repair.

Version D The contents of the scenario are the same as version A except for ...

* Unfortunately, on 1 January 2009, the car was vandalised by an unknown person and this made the customer suffer a loss of NT\$100,000 for the car repair.

** On the basis of Q's knowledge, Q knows that there is only a 30 per cent chance that the claim department will pay the claim.

insurance salespeople's attitudes towards collusion, different questionnaires with different manipulations need to be assigned in the research design. Here, using questionnaires is considered acceptable. Third, using a questionnaire with scenarios is one of the simplest procedures that allows a large number of questions to be investigated.

Questionnaires with two scenarios were used in this study. After reading the scenarios, the responders were asked to respond to the questions assuming they were the salesperson in the scenarios. Scenario 1 is about a customer fraud in a contract renewal situation, and Scenario 2 is about an insider fraud in a non-covered loss situation. In Scenario 1, a customer had a car insurance policy with a validity period extending from 1 January 2008 to 31 December 2008. Unfortunately, the car was vandalised by an unknown person on 1 January 2009. The customer agreed to renew the insurance policy for the following year if the salesperson applied for the claim and said the loss was caused on 31 December 2008. Notice that there is no automatic renewal in Taiwan. The insurance companies in Taiwan must inform customers of the coming expiration in "written form" and then the customers decide whether or not they will renew the auto body damage insurance. If the customers decide not to renew the insurance without interruption, then the original insurance policies lose their effectiveness after the expiration date.

In Scenario 2, the loss from vandalism was not covered by the insurance policy. However, in exchange for the contract renewal for the following year, the salesperson told the customer that he would apply for the claim and say the loss was caused by a natural disaster (natural disaster is covered by the insurance policy).

Scenario 1 focused on customer fraud. According to the description of Scenario 1, the insurance salesperson knows that the loss did not occur in the coverage period, and 
Table 2 Scenario 2 (Insider fraud)

\begin{tabular}{|c|c|}
\hline Version A & $\begin{array}{l}\text { "W" is a car insurance salesperson. A customer of W's had a car insurance policy. According } \\
\text { to the insurance policy, the loss from vandalism was NOT covered. Unfortunately, the car was } \\
\text { vandalised by an unknown person and this made the customer suffer a loss of NT\$5,000 for } \\
\text { the car repair. W knew that the insurance period had nearly expired. In exchange for the } \\
\text { contract renewal for the following year, W said to the customer that he would apply for the } \\
\text { claim and say that the loss was caused by a natural disaster (while natural disaster is covered } \\
\text { by the insurance policy). Finally, the customer decided to renew the policy. } \\
\text { On the basis of W's knowledge, W knows that the claims department will definitely pay the } \\
\text { claim. }\end{array}$ \\
\hline Version B & $\begin{array}{l}\text { The contents of the scenario are the same as version A except for ... } \\
\text { on the basis of W's knowledge, W knows that there is only a } 30 \text { per cent chance that the claims } \\
\text { department will pay the claim. }\end{array}$ \\
\hline Version $\mathrm{C}$ & $\begin{array}{l}\text { The contents of the scenario are the same as version A except for ... } \\
* \text { Unfortunately, the car was vandalised by an unknown person and this made the customer } \\
\text { suffer a loss of NT } \$ 100,000 \text { for the car repair. }\end{array}$ \\
\hline Version D & $\begin{array}{l}\text { The contents of the scenario are the same as version B except for ... } \\
\text { * Unfortunately, the car was vandalised by an unknown person and this made the customer } \\
\text { suffer a loss of NT } \$ 100,000 \text { for the car repair. } \\
\text { ** On the basis of W's knowledge, W knows that there is only a } 30 \text { per cent chance that the } \\
\text { claims department will pay the claim. }\end{array}$ \\
\hline
\end{tabular}

the policyholder did not renew the insurance on 1 January 2009. If the contract had been renewed on 1 January 2009, the customer would not have to make such a request to the insurance salesperson. (In the scenario we mentioned that: To obtain the insurance money, the customer asked $Q$ to apply for the claim and say the loss was caused on 31 December 2008.) If the customer in this case applied for the contract renewal to the company and paid the premium after 1 January 2009 (e.g. on 5 January 2009), the new contract would come into effect on the date that insurance premium was paid.

The source of the customer fraud in Scenario 1 is information asymmetry. The insurer may be unable to observe the customer and the salesperson's collusive behaviour prior to or after the risk event, and therefore the customer can collude with the salesperson without the knowledge of the insurer. The opportunity to obtain the fraudulent claim was manipulated in two ways. In versions $A$ and $C$, the claim department would definitely pay the claim. However, we mentioned in versions B and $\mathrm{D}$ that the opportunity to obtain the fraudulent claim was only 30 per cent. Loss sizes were also manipulated in the scenarios in two ways. As can been seen in Table 1, the loss size in versions A and B was smaller (NT\$30 is about US\$1 in February 2012) than the loss size in versions $\mathrm{C}$ and $\mathrm{D}$ (Table 2).

Scenario 2 focused on insider fraud. In Scenario 2, in exchange for the contract renewal for the following year, salesperson "W" would like to help the customer to apply for the loss that is not covered by the policy. Similarly, the opportunity to obtain the fraudulent claim and the loss sizes were manipulated at two levels. 


\section{Measurement}

Before reading the scenarios, each responder was required to answer two questions. The questions are about their perceived stress in goal achievement and customer orientation (CO). We designed a question that asked the responders about their current feeling about the stress. The measure of stress in goal achievement was: I currently feel very stressed about achieving the contract renewal rate in my company, which was adopted from Schwepker's ${ }^{17}$ research. Another question about CO was asked: I always try my best to satisfy the needs of my customers. The item was adopted from Saxe and Weitz's ${ }^{18}$ research. The items were measured by 7-point Likert type scales anchored with "totally agree" to "totally disagree". When the questions were answered, responders turned to the next page, which presented the two scenarios.

In this research, the dependent variables for the scenarios are: the need to obtain the renewal, EA, perceived peer behaviour and ethical intention. Our measurements of EA and the need to obtain the renewal were adapted from Ajzen. ${ }^{19}$ Again, a 7-point scale (from totally agree to totally disagree; totally agree $=7$ and totally disagree $=1$ ) was used. The measurements of perceived peer behaviour were adapted from Joseph et al. ${ }^{20}$ research. Ethical intention was measured in two ways. First, this research asked responders whether they would apply for the claim if they were the salesperson in the scenarios. A 7-point scale (from totally agree to totally disagree; totally agree $=7$ and totally disagree $=1$ ) was used. Second, this research asked responders how much money they would apply for if they were the salesperson in the scenarios. The responders needed to write down the amount of money. The items were presented in Table 3. Notice that indirect questions are used to alleviate the problem of social desirability responses. ${ }^{21}$

\section{Sample}

A between-subject experiment was conducted at five non-life insurance companies (purposive sampling was used) in Taiwan, from 10 December 2011 to 11 February 2012. All the responders in this study are full-time, licensed car insurance salespeople. We contacted the top managers of these non-life insurance companies, and then arranged the formal investigation after receiving agreement from the managers. During the formal investigations, the questionnaires brought by researchers were distributed and collected by the managers and then returned to the researchers (each responder was given a questionnaire randomly from the top manager in the organisation). The returned questionnaires were not put into sealed envelopes but taken away by the researchers. To ensure the confidentiality of the data, in the cover letter we mentioned that There is no right or wrong answer, and we promise that the questionnaire is anonymous and your answers are confidential. In sum, a total of 310

\footnotetext{
${ }^{17}$ Schwepker (1999).

${ }^{18}$ Saxe and Weitz (1982).

19 Ajzen (2005).

${ }^{20}$ Joseph et al. (2009).

${ }^{21}$ Piquero et al. (2002).
} 
Table 3 Items and measurement

\begin{tabular}{lll}
\hline Items & Questions & Constructs \\
\hline Item 1 & If I were the salesperson, I think I would need to obtain the renewal. & Renewal \\
Item 2 & I think what the salesperson did is not wrong. & Ethical attitude \\
Item 3 & If my peers were the salesperson, I think they would apply for the claim. & Peers behaviour \\
Item 4 & If I were the salesperson, I would apply for the claim. & Intention \\
Item 5 & $\begin{array}{l}\text { If I were the salesperson, how much money should I apply for in the claim? } \\
\text { Write in a dollar amount }\end{array}$ & Claim amount \\
\hline
\end{tabular}

Table 4 Sample

\begin{tabular}{lcc}
\hline Versions & & \\
A & 63 & $26.5 \%$ \\
B & 56 & $23.5 \%$ \\
C & 65 & $27.3 \%$ \\
D & 54 & $22.7 \%$ \\
Gender & & $53.4 \%$ \\
Female & 127 & $46.6 \%$ \\
Male & 111 & \\
Age & & $23.6 \%$ \\
$20-29$ & & $33.8 \%$ \\
$30-39$ & 56 & $31.2 \%$ \\
$40-49$ & 80 & $11.4 \%$ \\
$50-59$ & 74 & \\
Education & 27 & $9.7 \%$ \\
Post-graduate degree & & $54.9 \%$ \\
Bachelor's degree & & $22.8 \%$ \\
5 years of college & 23 & $12.2 \%$ \\
High school degree or less & 130 & $63.4 \%$ \\
Current position & 54 & $36.6 \%$ \\
With managerial work & 29 & \\
No managerial work & & 86 \\
\hline
\end{tabular}

Note: Missing value is not included.

questionnaires were issued and with 238 questionnaires returned (a valid return rate of 76.8 per cent). To blind our samples to the experimental manipulations, each responder only received one version of the questionnaire. Females comprised 53.4 per cent of the sample. Over 36 per cent of the respondents were in managerial work. The characteristics of the samples are outlined in Table 4. 
Analysis

The dependent variables were measured on an ordinal scale. Hence, non-parametric statistics such as Spearman's rho test, Mann-Whitney-Wilcoxon test (MWW), a Kruskal-Wallis test (KW) and a Wilcoxon signed-rank test were used.

\section{Results}

\section{Correlations}

The correlation coefficients for the stress in goal achievement (Goal), $\mathrm{CO}$, the need to obtain the renewal (Renewal), EAs, intentions and claim amount (Claim) are in Table 5 (Scenario 1). The correlation coefficients indicated that the responders' perceived stress in goal achievement was positively correlated with the need to obtain the renewal (the coefficient $=0.170, p<0.01$ ), indicating that when perceived stress in goal achievement was high, the responders' need to obtain the renewal was also high. The responders' perceived stress in goal achievement was also positively correlated with EAs (the coefficient $=0.131, p<0.05$ ), showing that when perceived stress in goal achievement was high, the responders may believe that helping the dishonest customer was not ethically wrong. It seemed that the responders' perceived stress in goal achievement was correlated with the belief of peer behavioural intentions (the coefficient $=0.166, p<0.05$ ). In other words, when perceived stress in goal achievement was high, the responders would hold higher beliefs that their peers would perform the unethical conduct in Scenario 1. The belief of peer behavioural intention was correlated with the responders' ethical intention (the coefficients $=0.614$ and 0.559 , $p<0.01$, respectively). The findings further suggested that believed peer behaviour, EA and ethical intention were correlated to the claim amounts. We did not find any significant relationship between $\mathrm{CO}$ and the dependent variables.

The correlation coefficients among scale items for Scenario 2 are presented in Table 6. Similarly, the correlation between the stress for goal achievement and believed peer behaviour was significant $(0.144, p<0.05)$. Believed peer behaviour was correlated with the intention to help the dishonest customer to apply for the claim (the coefficient $=0.663$ and $0.501, p<0.01$ ). The results of Spearman's rho test also showed a positive correlation between EAs and intentions, which reached the level of significance $(0.742, p<0.01)$.

Table 5 Correlation between scale items for Scenario 1

\begin{tabular}{|c|c|c|c|c|c|c|c|}
\hline & 1. Goal & 2. $\mathrm{CO}$ & 3. Renewal & 4. $E A$ & 5. Peers & 6. Intention & 7. Claims \\
\hline 1. & 1 & & & & & & \\
\hline 2. & -0.078 & 1 & & & & & \\
\hline 3. & $0.170^{* *}$ & 0.110 & 1 & & & & \\
\hline 4. & $0.131^{*}$ & -0.052 & 0.011 & 1 & & & \\
\hline 5. & $0.166^{*}$ & -0.026 & $0.243^{* *}$ & $0.734 * *$ & 1 & & \\
\hline 6. & 0.107 & -0.003 & $0.188 * *$ & $0.737 * *$ & $0.614^{* *}$ & 1 & \\
\hline 7. & -0.046 & -0.007 & 0.105 & $0.621 * *$ & $0.559 * *$ & $0.627^{* *}$ & 1 \\
\hline
\end{tabular}

$* p<0.05 ; * * p<0.01$. 
Table 6 Correlation between scale items for Scenario 2

\begin{tabular}{lcrccccc}
\hline & 1. Goal & 2. CO & 3.Renewal & 4.EA & 5.Peers & 6.Intention & 7.Claim \\
\hline 1. & 1 & & & & & & \\
2. & -0.078 & 1 & & & & & \\
3. & $0.258^{* *}$ & -0.018 & 1 & & & & \\
4. & 0.072 & 0.024 & $0.158^{*}$ & 1 & & & \\
5. & $0.144^{*}$ & 0.054 & $0.285^{* *}$ & $0.737^{* *}$ & 1 & & \\
6. & 0.119 & -0.017 & $0.252^{* *}$ & $0.742^{* *}$ & $0.663^{* *}$ & 1 & 1 \\
7. & 0.016 & 0.069 & $0.193^{* *}$ & $0.482^{* *}$ & $0.501^{* *}$ & $0.626^{* *}$ & 1 \\
\hline
\end{tabular}

$* p<0.05 ; * * p<0.01$.

\section{Manipulation checks}

We proposed two hypotheses in the research. Hypothesis 1 stated that car insurance salespeople would be more likely to engage in collusion when the perceived opportunity to obtain the fraudulent claim is high rather than low. Hypothesis 2 stated that car insurance salespeople would be more likely to engage in collusion when the actual loss is small rather than large. The two hypotheses also reflected the experimental manipulations (the opportunity to obtain the fraudulent claim and the size of actual loss) of the research design.

The mean values for the dependent variables in Scenario 1 are in Table 7. The mean value for obtaining the renewal (Renewal) in version A was 4.810, and 5.292 in version $\mathrm{C}$, indicating that, as the fraud size grew from 5,000 to 100,000 , the need to obtain the renewal would become slightly higher. The mean value for the EA in version A was 3.529 , and 2.946 in version $\mathrm{B}$, indicating that, as the opportunity to obtain the fraudulent claim decreased from 100 per cent to 30 per cent, the responders in version A may recognise the misconduct as more acceptable. In Table 7, it seemed that the opportunity to obtain the fraudulent claim and fraud size may also result in a change of claim amounts. For example, the responders in version D scored the question "If you were the car owner, how much money do you think you would apply for in the claim?" lower than version C did (mean value $=34326.9$ for version $D$, while mean value $=44161.2$ for version $C$ ). This indicates that the responders would apply for lower claims when the opportunity to obtain the fraudulent claim was low.

Interestingly, the customer should obtain nothing from the insurer in all questionnaires, and the responders should not apply for the claim because the loss was caused on 1 January 2009. However, the mean values in Table 7 showed that some responders may still apply for the claims no matter which experimental manipulation was employed. Moreover, the actual loss was NT\$5,000 in versions A and B, and NT\$100,000 in versions C and D. However, according to the mean values in Table 7, the responders who received versions $\mathrm{A}$ and $\mathrm{B}$ would apply for the claim, which was higher than NT\$5,000 (they applied for NT\$6,080.4 and NT\$5,648.2 on average), while the responders who received versions $\mathrm{C}$ and $\mathrm{D}$ would apply for the claim, which was much lower than the actual loss. Thus, it seems that the size of the actual loss could be a factor that affects the responders' decisions in customer fraud problems. 
Table 7 Means for Scenario 1

\begin{tabular}{lcccc}
\hline Constructs & Version $A$ & Version $B$ & Version C & Version D \\
\hline 1. Renewal & 4.810 & 5.482 & 5.292 & 5.056 \\
2. EA & 3.529 & 2.946 & 3.030 & 2.870 \\
3. Peers & 4.191 & 3.929 & 4.169 & 3.796 \\
4. Intention & 3.557 & 3.589 & 3.415 & 3.148 \\
5. Claims & 6080.4 & 5648.2 & 44161.2 & 34326.9 \\
\hline
\end{tabular}

Note: Mean value $=7$ refers to totally agree.

To compare the impacts caused by the experimental manipulations, a post-hoc analysis was conducted. $p$ values for MWW test and KW test for Scenario 1 (Scenario 1 focused on customer frauds) are shown in Table 8 . As can be seen in the table, the responders in version $A$ revealed a lower need to obtain the renewal than the responders in version $\mathrm{B}$ (see $\mathrm{A} / \mathrm{B}, p=0.038$ ), indicating that the opportunity to obtain the fraudulent claim could be a factor that affects the responders' decisions in customer fraud problems. The KW test showed that the responders scored the final question (how much money should I apply for in the claim?) differently across the versions $(p=0.012)$. Other results were basically insignificant.

Scenario 2 focused on an insider fraud in a non-covered loss situation. The mean value of each independent variable for Scenario 2 can be seen in Table 9. Again, it seemed that the responders in version A scored a higher EA (mean=3.387) than the responders in versions $\mathrm{B}$ and $\mathrm{C}$. This indicates that the responders believed the insider fraud was more acceptable when the actual loss was small and when the opportunity to obtain the fraudulent claim was high (version A). Yet, in contrast to the findings in Scenario 1, the responders in Scenario 2 would apply for the claim, which was much lower than the actual loss (see that in versions A and B, they applied for NT\$3,907.4 and NT\$3,615.4 on average). The responders who received versions $\mathrm{C}$ and $\mathrm{D}$ would still apply for the claim, which was much lower than the actual loss (NT\$27,288.1 and NT\$24,423.1 on average) (Table 10).

The manipulation check for Scenario 2 showed that the manipulations did not work as expected. Only two significant results were found in the table. The results of the MWW for versions A and C (see A/C) showed that the responders in version A would tend to accept the insider fraud significantly more than the responders in version $\mathrm{C}$ $(p=0.005)$. The results of the $\mathrm{KW}$ test showed that there was a significant difference in EAs among versions $(p=0.037)$.

\section{Customer frauds vs insider frauds}

We only found few significant results in the manipulation checks. However, when the mean values of Scenarios 1 and 2 were compared, it was found that many of the results were significantly different. The Wilcoxon signed-rank test was employed to compare the values of responses from two related samples. Table 11 showed that the presence of fraud types (customer fraud vs insider fraud) could affect the responder perceptions of the need to obtain the renewal, EA, belief in peer behaviour and the responders' 
Table 8 Mann-Whitney-Wilcoxon (MWW) and Kruskal-Wallis (KW) for Scenario 1

\begin{tabular}{lllllll}
\hline Scenario 1: & Version & Renewal & EA & Peers & Intention & Claims \\
\hline MWW & A/B & $0.038^{*}$ & 0.162 & 0.434 & 0.980 & 0.930 \\
& A/C & 0.185 & 0.212 & 0.830 & 0.648 & $0.008^{* *}$ \\
& A/D & 0.487 & 0.101 & 0.257 & 0.269 & $0.033^{*}$ \\
& B/C & 0.323 & 0.803 & 0.500 & 0.616 & $0.016^{*}$ \\
& B/D & 0.178 & 0.760 & 0.713 & 0.330 & 0.062 \\
& C/D & 0.580 & 0.575 & 0.293 & 0.497 & 0.293 \\
KW & A/B/C/D & 0.185 & 0.336 & 0.612 & 0.681 & $0.012^{*}$ \\
\hline
\end{tabular}

$* p<0.05 ; * * p<0.01$.

Table 9 Means for Scenario 2

\begin{tabular}{lcccc}
\hline Constructs & Version $A$ & Version $B$ & Version C & Version D \\
\hline 1. Renewal & 4.693 & 4.482 & 4.692 & 4.611 \\
2. EA & 3.387 & 2.929 & 2.446 & 3.000 \\
3. Peers & 3.919 & 3.518 & 3.323 & 3.759 \\
4. Intention & 3.516 & 2.946 & 2.908 & 3.482 \\
5. Claims & 3907.4 & 3615.4 & 27288.1 & 24423.1 \\
\hline
\end{tabular}

Note: Mean value $=7$ refers to totally agree.

Table 10 Mann-Whitney-Wilcoxon (MWW) and Kruskal-Wallis (KW) for Scenario 2

\begin{tabular}{lllllll}
\hline Scenario 1: & Version & Renewal & EA & Peers & Intention & Claims \\
\hline MWW & A/B & 0.548 & 0.197 & 0.220 & 0.118 & 0.597 \\
& A/C & 0.873 & $0.005^{* *}$ & 0.066 & 0.085 & 0.889 \\
& A/D & 0.917 & 0.274 & 0.641 & 0.940 & 0.077 \\
& B/C & 0.475 & 0.129 & 0.558 & 0.883 & 0.989 \\
& B/D & 0.691 & 0.810 & 0.487 & 0.166 & 0.101 \\
& C/D & 0.845 & 0.076 & 0.198 & 0.117 & 0.624 \\
KW & A/B/C/D & 0.908 & $0.037^{*}$ & 0.272 & 0.174 & 0.437 \\
\hline
\end{tabular}

$* p<0.05 ; * * p<0.01$.

intention to apply for the claim. The results showed that the responders in version A may hold a higher need to obtain the renewal in customer fraud than insider fraud ( $t$ value $=-3.649 ; p=0.000)$. Similar results were found in other versions as well (e.g. $t=-4.222$ and $p=0.000$ in version B). Moreover, the responders in version A may have a higher acceptance of customer fraud rather than insider fraud $(t=-3.846$; $p=0.004)$. Specifically, the responders held higher beliefs that peers would apply for the claim in Scenario 1 (e.g. $t=-2.800$ and $p=0.005$ in version A). Some significant results were also found for intentions and claim amounts. In summary, the significant differences in the mean values between Scenarios 1 and 2 may indicate that the responders had different reactions to customer fraud and insider fraud. It seems that 
Table 11 Wilcoxon signed-rank test

\begin{tabular}{|c|c|c|c|c|c|}
\hline & Renewal & $E A$ & Peers & Intention & Claims \\
\hline \multirow[t]{2}{*}{ Version A } & -3.649 & -3.846 & -2.800 & -0.044 & -1.189 \\
\hline & 0.000 & 0.004 & 0.005 & 0.965 & 0.235 \\
\hline \multirow[t]{2}{*}{ Version B } & -4.222 & -4.178 & -3.319 & -2.659 & -1.823 \\
\hline & 0.000 & 0.000 & 0.001 & 0.008 & 0.068 \\
\hline \multirow[t]{2}{*}{ Version C } & -3.887 & -4.182 & -5.437 & -2.902 & -3.015 \\
\hline & 0.000 & 0.000 & 0.000 & 0.004 & 0.003 \\
\hline \multirow[t]{2}{*}{ Version D } & -3.317 & -4.054 & -2.412 & -1.051 & -1.850 \\
\hline & 0.001 & 0.000 & 0.016 & 0.293 & 0.064 \\
\hline
\end{tabular}

the presence of customer fraud may enhance the responders' attempt to pad insurance claims. The literature on the comparison between insider and customer fraud has been very rare. The findings may have some implications for insurance fraud research.

\section{Discussions}

Insurance fraud has been described as extremely harmful behaviour in the insurance industry. However, both customer fraud and insider fraud are still occurring in reality. Although prior work on insurance fraud has found that EA and deductible amounts may affect policyholders' ethical decision-making in frauds, ${ }^{22}$ very few of them discussed insurance salespeople's intention to perform the unethical behaviour when different actual losses, the opportunity to obtain the fraudulent claim and fraud types (customer fraud vs insider fraud) are considered. Early survey work on insurance frauds also seldom studied the roles of reciprocity between the insiders and customers, and the contract renewal and insurance coverage were less mentioned as well. Therefore, by taking the car insurance industry as an example, this study has provided an empirical observation of how car insurance salespeople would react to salespeople-customer collusion when contract renewal is presented.

Some important conclusions of the study are: (1) It seems that Hypothesis 2 was supported. The size of actual loss may affect how much money the responders would apply for the customers. We show that a small size of actual loss may provide a stronger incentive to encourage the responders to pad the claim. (2) It seems that Hypothesis 1 was not supported. We did not find significant results that the opportunity to obtain the fraudulent claim will affect the final claim amounts. Yet, Tables 7 and 9 showed that the claim amounts would be lower when the opportunity to obtain the fraudulent claim was small. (3) In the scenarios, the customer should obtain nothing from the insurer. However, the results of this study showed that some responders would still apply for the claims, especially in the customer fraud

${ }^{22}$ Tennyson (1997, 2002); Dean (2004); Brinkmann and Lentz (2006); Miyazaki (2009). 
scenario. (4) Finally, the responders would react differently to customer fraud and insider fraud. It seems that customer fraud was more tolerable to car insurance salespeople.

Some implications of this study were proposed. First, in economic fraud, it is true that customers and insiders can form a binding agreement. Yet, it seems that the researchers interested in frauds or economic collusion have ignored the impacts of exchange structures (e.g. negotiated, reciprocal and generalised exchange). We believe that some frauds are conducted in an interpersonal context, and thus social exchange theory could be applied in the economic fraud study. Second, the results of this study give support to the impacts of the stress in goal achievement and Jones' magnitude of consequences. We think practitioners can influence customer frauds and insider frauds by focusing on stress management and claim management. A clear claim policy that ensures all frauds are unacceptable may reduce salespeople's tolerance of frauds. Third, it seems that customer frauds are more likely to encourage the responders to sacrifice the insurer's interests. Since salespeople are expected to satisfy the financial needs of customers and to build a good relationship with the customers, we think exposing customer fraud to management is not easy for salespeople. We suggest insurers should provide ethical training and a clear policy to the salespeople, and indicate that customer fraud is not allowed in the company.

\section{The investigation has some limitations}

First, this paper explored the impacts of the opportunity to obtain the fraudulent claim and the size of actual loss on car insurance salespeople's attitudes towards collusion in situations involving contract renewal and non-covered loss. There seems to be no secondary data to show car insurance salespeople's attitudes towards collusion. Using questionnaires may help us to gather the information. However, instead of measuring car insurance salespeople's attitudes directly, it would be interesting if researchers could use some database in which the insurance companies had collected data on the presence of this type of fraud and the damages derived.

Second, due to the selection of some Taiwanese car insurance salespeople as respondents, one of the limitations of this study is the lack of generalisability of the results. Generalising from the findings of this study is also problematic in light of the fact that results are based on two artificial scenarios. The responders did not need to consider real-world problems (e.g. punishments in the real world).

Third, the ways scenarios are phrased can affect the responses, and we are unsure how responders may have interpreted the wording in the scenarios. It was suggested that researchers could use a pilot test to ascertain how well the questionnaire worked. ${ }^{23}$ Administering the questionnaire to a small group of respondents may help researchers refine the questionnaire wording, based on the respondents' feedback. Researchers could also divide respondents into two or more groups, and then different scenario wording can be assigned to these groups so that wording effects may be observed.

\footnotetext{
${ }^{23}$ Schwab (2005).
} 


\section{Acknowledgements}

The authors thank Mr. He Meng-Jie and Mr. Yang Meng-Hsin for assisting with data collection.

\section{References}

Ajzen, I. (2005) Attitudes, Personality, and Behavior, Maidenhead, UK: Open University Press.

Arrow, K. (1963) 'Uncertainty and the welfare economics of medical care', American Economic Review 53(5): 941-973.

Brinkmann, J. and Lentz, P. (2006) 'Understanding insurance customer dishonesty: Outline of a moral-sociological approach', Journal of Business Ethics 66(2/3): 177-195.

Chen, M.F., Pan, C.T. and Pan, M.C. (2009) 'The joint moderating impact of moral intensity and moral judgment on consumer's use intention of pirated software', Journal of Business Ethics 90(3): 361-373.

Cohen, L.E. (1981) 'Modeling crime trends: A criminal opportunity perspective', Journal of Research in Crime and Delinquency 18(1): 138-164.

Dean, D.H. (2004) 'Perceptions of the ethicality of consumer insurance claim fraud', Journal of Business Ethics 54(1): 67-79.

Dionne, G. and Gagné, R. (2001) 'Deductible contracts against fraudulent claims: Evidence from automobile insurance', Review of Economics and Statistics 83(2): 290-301.

Dionne, G. and St-Michel, P. (1991) 'Workers compensation and moral hazard', Review of Economics and Statistics 73(2): 236-244.

Dooley, D. (2001) Social Research Methods, Upper Saddle River, NJ: Prentice-Hall.

Haines, R., Street, M.D. and Haines, D. (2008) 'The influence of perceived importance of an ethical issue on moral judgment, moral obligation, and moral intent', Journal of Business Ethics 81(2): 387-399.

Jones, T.M. (1991) 'Ethical decision making by individuals in organizations: An issue-contingent model', Academy of Management Review 16(2): 366-395.

Joseph, J., Berry, K. and Deshpande, S.P. (2009) 'Impact of emotional intelligence and other factors on perception of ethical behavior of peers', Journal of Business Ethics 89(4): 539-546.

LaGrange, T.C. and Silverman, R.A. (1999) 'Low self-control and opportunity: Testing the general theory of crime as an explanation for gender differences in delinquency', Criminology 37(1): 41-72.

Miyazaki, A.D. (2009) 'Perceived ethicality of insurance claim fraud: Do higher deductibles lead to lower ethical standards?' Journal of Business Ethics 87(4): 589-598.

Molm, L.D., Takahashi, N. and Peterson, G. (2000) 'Risk and trust in social exchange: An experimental test of a classical proposition', American Journal of Sociology 105(5): 1396-1427.

Nykodym, N., Taylor, R. and Vilela, J. (2005) 'Criminal profiling and insider cyber crime', Digital Investigation 2(4): 261-267.

Picard, P. (2000) 'Economic analysis of insurance fraud', in G. Dionne (ed.) Handbook of Insurance, Boston, MA: Kluwer Academic Publishers, pp. 315-362.

Piquero, A.R. and Tibbetts, S.G. (eds) (2002) Rational Choice and Criminal Behavior: Recent Research and Future Challenges, New York: Routledge.

Saxe, R. and Weitz, B.A. (1982) 'The SOCO scale: A measure of the customer orientation of salespeople', Journal of Marketing Research 19(3): 343-351.

Schwab, D.P. (2005) Research Methods for Organizational Studies, Mahwah, NJ: Lawrence Erlbaum Associates.

Schwepker, C.H. (1999) 'Understanding salespeople's intention to behave unethically: The effects of perceived competitive intensity, cognitive moral development and moral judgment', Journal of Business Ethics 21(4): 303-316.

Singhapakdi, A., Vitell, S.J. and Kraft, K.L. (1996) 'Moral intensity and ethical decision-making of marketing professionals', Journal of Business Research 36(3): 245-255.

Tennyson, S. (1997) 'Economic institutions and individual ethics: A study of consumer attitudes toward insurance fraud', Journal of Economic Behavior and Organization 32(2): 247-265.

Tennyson, S. (2002) 'Insurance experience and consumers' attitudes toward insurance fraud', Journal of Insurance Regulation 21(2): 35-55. 
Viaene, S. and Dedene, G. (2004) 'Insurance fraud: Issues and challenges', The Geneva Papers on Risk and Insurance-Issues and Practice 29(2): 313-333.

\section{About the Authors}

Dr Tseng Lu-Ming is Assistant Professor in the Department of Risk Management and Insurance, Feng Chia University (Taiwan). His research interests are in the areas of Insurance Marketing and Behavioural Economics. Before beginning his academic career, He was a sales trainer and held training programmes for insurance salespeople.

Dr Su Wen-Pin was Associate Professor in the Department and Graduate Institute of Insurance, Chaoyang University of Technology (Taiwan). His research interests were in the areas of Automobile Insurance, Liability Insurance and the national pension system. He published a number of books in non-life insurance, monetary banking and statistics. He also served as a consultant to several non-life insurance companies and other private corporations. 